\title{
The Problems Faced by Physiotherapy Students and Their Causes in Completing Reading Comprehension Section of ITP TOEFL
}

\author{
Meladina Meladina ${ }^{1}$ and Dasril Dasril ${ }^{2}$ \\ ${ }^{1}$ Universitas Fort De Kock Bukittinggi, Indonesia \\ ${ }^{2}$ Universitas Negeri Padang, Padang, Indonesia
}

\begin{abstract}
ARTICLE HISTORY
Received : 10 May 2021

Revised : 21 May 2021

Accepted : 26 July 2021
\end{abstract}

\section{KEYWORDS}

\section{TOEFL}

Non-English Students

Physiotherapy Students

Reading

Reading Comprehension Section

Types of Reading Questions

Problems in Reading

\begin{abstract}
TOEFL is an important English test that should be taken by all university students from all the study programs in Indonesia. Each student needs to know all English skills tested and master those skills as well. This study was conducted to investigate the difficulties faced by non-English students, namely students of physiotherapy study program with section three reading comprehension of International Testing Program (ITP) TOEFL as well as the causes of difficulties encountered. The type of this research was descriptive quantitative. Using total sampling technique, all of 36 physiotherapy students in the University of Fort De Kock Bukittinggi were chosen as the samples. The data were collected through a multiple-choice test consisting of 50 questions with four options and questionnaire. The data were then analyzed using Roger's 2011 theory on the seven types of questions of reading tested in ITP TOEFL. The results showed that all of the students had problems with main idea (24.0\%), factual question (26.1\%), inference question (26.3\%), vocabularies in-context (29.4\%), and negative question $(34.4 \%)$ (difficult questions, scanning (13.8\%) and reference question $(18.0 \%)$ (the most difficult questions. These problems are caused by a number of factors such as feeling panic to face long passages, limitation of vocabularies, lack of practice, and less motivation. Therefore, English teachers and trainers are strongly encouraged to pay more attention to the reading problems faced by the students in ITP TOEFL as well as the causes of the problems by facilitating and providing more study exercises and practice.
\end{abstract}

\section{Introduction}

The Test of English as a Foreign Language (TOEFL) is a test used to measure the ability of non-native speaker of English in comprehending English. Nurhayati, (2016)stated that TOEFL test is a standardized proficiency test used to measure the ability of students who use English as a foreign language. Then, Noviyenty(2018) claimed that TOEFL is a standard English test that can be accepted internationally and is used to assess non-native speaker's proficiency in English. Furthermore, Educational Testing Service in their website (Services, n.d.) explained that TOEFL can be used by universities in USA and has been trusted by 150 countries to assess the ability of someone in English. This statement is in line with Abboud \& Husseinin Ananda (2016) who stated that there are more than 5,000 colleges, universities, and agencies in 90 countries that accept the TOEFL scores as one of the required documents. In short, TOEFL test is a test used to measure the ability non-native speakers in English and the TOEFL score can be accepted by overseas universities in many countries around the world.

In Indonesia, TOEFL is an important English test that should be taken by all of the students from all of the study programs. Most of the universities in Indonesia recommend their students to get a particular TOEFL score to complete their study in the university. They may take an official paper- based test (PBT), usually referred to international testing program (ITP). ITP TOEFL test is an important English test for students due to a number of important reasons such as completing their study, continuing their study to a higher level, getting scholarships, and applying for a job.

In University of Fort De Kock Bukittinggi in Indonesia, it is stated in its regulation that the students are required to take ITP TOEFL test before accomplishing their study in that university even though in its implementation it hasn't been fully implemented. Referring to this regulation, all students in this university are expected to have sufficient knowledge and good English skills so that they can get high ITP TOEFL scores.

However, based on the researchers' preliminary research conducted in Fort De Kock University Bukitttinggi in 2018, from all of the students in five study programs: Nursing, Midwifery, Physiotherapy, Pharmacy, and Public Health consisting of 642 students, it was found that the highest score of their TOEFL prediction test was 486 and the lowest one was 385 . The average of their score was 300 to 350 . It means that most of the students got lower score in completing TOEFL prediction. By analyzing these data, it can be concluded that the students do not have sufficient proficiency in English. Moreover, based on the interview done to a number of students who had taken the test, they 
stated that they found a number of problems in answering the reading section. Such problems might be caused by a number of reasons. Therefore, it is important to be researched.

There are a number of reasons why this research needs to be conducted. First, most of the previous researchers conducted the researches on English department students. They analyzed the ability of the English department students in completing TOEFL test. Meanwhile, this study was done on non-English students especially health science department (Physiotherapy study program) who are also recommended to take ITP TOEFL to finish their study, to continue their study, to get a scholarship and others. The second reason is the indicators used to analyze the reading comprehension section. The previous researchers applied Carrel (2006) theory that describes some aspects in reading comprehension tested in ITP TOEFL: main idea, detail information, vocabularies and inference. However, in this research the researchers used Rogers (2011)theory that has more elements in analyzing the aspects of reading comprehension in ITP TOEFL. These reasons also make this research different from the previous researches.

Next, this research was also expected to give valuable contribution both theoretically and practically for EFL teachers and learners. Theoretically, this study is expected to enrich the existing theories about the problems faced by nonEnglish students in reading comprehension part of ITP TOEFL so that it can be used as a reference for other researchers who want to conduct further studies. Practically, this study can help EFL teachers and students find better strategies that can be used to improve their ITP TOEFL score. Based on this reality found in the field, it was interesting to conduct a research to find out the problems faced by the students in ITP TOEFL especially in section three on reading comprehension, as well as its reasons.

\section{Literature Review}

\subsection{Reading Comprehension Section in ITP TOEFL}

Reading is one of the skills in learning a language. According to Meladina (2013), reading is one of the skills in learning a language that includes a text, reader, and the interaction between both of them. Furthermore, in ITP TOEFL, Reading comprehension is one of the largest and complicated sections. It has many kinds of texts and task models provided (Sungatullina et al., 2016). In addition, it has many aspects of reading tested. According to Sari (2019), the aspects of reading tested in ITP TOEFL are main idea, detail information, vocabulary, and inference. The main idea is key or central thought or message. It also refers to the point or thought being expressed. Then, detail information may include facts, statements, examples-specifics that may guide readers to understand the whole text. It can be called as supporting detail. Vocabulary is another aspect of reading comprehension in ITP TOEFL. Students' vocabulary knowledge is related to reading comprehension and academic success. This relationship may lead them to understand the meaning of the text. Next, inference is the ability to read between the lines or to get the meaning of the writers' implications in the text. It also requires a reader to take a note from text clues, access prior knowledge or background knowledge and predict (infer) the meaning of that text.

Furthermore, Rogers (2011), mentioned that there are seven types of questions of reading that usually appear in ITP TOEFL. The first type is main idea. Main idea refers to a subject that may describe the whole passage or a reason why the writer writes a passage. This type of question appears about $10 \%$ of the questions in ITP TOEFL. The second type is factual question (stated detail/detail information). The factual questions include the questions about specific information or detail information about a passage. The question may begin with where, who, when, or which one. These questions may appear $24 \%$ from all of the questions in reading section. The third type is negative question. These questions ask about the answer choice that cannot be found in the passage provided. The samples of the questions are such as "Which of the following is NOT true about...", "All of the following are true EXCEPT...". Such questions appear around $9 \%$ in ITP TOEFL.

Scanning question is another type of reading question in ITP TOEFL. This question asks where a topic is mentioned (4\%). Then, inference questions ask readers to draw a conclusion based on the information they can get from the passage. The samples of the questions are such as "The author implies that which of the following is true?", "Which of the following can be inferred from the passage". The total of type of these questions are around $12 \%$. Next, the reading section of ITP TOEFL has vocabulary-in-context question. In this type of question, a reader is asked to identify the meaning of a word or phrase in the passage. It appears about $26 \%$. Reference question is also included in the reading test of ITP TOEFL. This question asks a reader to find a noun to which a pronoun or other expressions refer to and appears around $10 \%$. In short, several types of questions tested in the reading comprehension section of ITP TOEFL are, main idea, factual question, negative question, scanning, inference question, vocabulary-in-context question and reference question.

\subsection{Reading Difficulties in TOEFL}

For some people, reading comprehension is considered as one of the difficult sections in ITP TOEFL. Because in this section, according to Antoni (2014)the students have problems in understanding the meaning of the text they read. In addition, they have problems to get the ideas from the passage provided. Furthermore, Maizarah (2019) states that the most difficult skill tested in reading comprehension especially in ITP TOEFL was identifying stated detail questions. It was around $84 \%$. Then, pronoun reference, and transition questions were the other major problems encountered by students in an ITP TOEFL test. Moreover, Jayanti (2016) in her research, found that lack of vocabulary was the most difficult problem faced by the students. It is because many students still depended on dictionary if they 
found new words or difficult words in the text. Therefore, it was hard for them to understand the meaning of the words; consequently, they got difficulties to comprehend the text well.

The second difficulty is syntactic and semantic analysis. It is hard for the students to understand the relationship and functions of words within sentences. This problem is deteriorated by long sentences which make them confused and hard to create meaning from the text. The students cannot differentiate the connotative and denotative meanings of words or text. Inferring lexical meanings also becomes another difficulty faced by students. It is difficult for them to understand the meaning beyond the text. Some of these problems are in line with Sharpe (2004) in Lestari (2017) awho said that there are nine problems in the reading section of the ITP TOEFL. They are previewing, reading for main ideas, using context for vocabulary, scanning for detail, making inference, identifying exception, locating reference, and reading faster.

Furthermore, the problems faced by students are caused by a number of reasons. According to Halim \& Ardiningtyas (2018) the reasons include lack of basic skill. It means that the students have low understanding about basic skill in English such as grammar. They should know about the basic level first, include a subject, pronoun, object pronoun, verb forms, and others. Lack of vocabulary may also be a cause of the students' difficulties. It makes students hard to find the synonym in reading section. Students' lack of practice can also contribute to reading problems. It occurs since they do not apply what they have learned. The indication is that the students did not do their best in their English class so that they did not have sufficient skill to answer the reading questions in ITP TOEFL. Moreover, less motivation is another reason for the reading difficulties. It means that students join the test only to fulfill the requirement without considering their need to assess themselves in English.

Then, the reading problems may stem from the students' individual differences. It is seen from the students' personal data especially their local language that will affect their ability in English especially in TOEFL test. Furthermore, Febriani et al., (2019) said that lack of reading strategies may cause the students' problems in reading comprehension of TOEFL test. The students are accustomed to looking up the dictionary if they find the unfamiliar words found in the text. These reading strategies are very crucial to be done because they not only help to understand the text but also may solve the problems (Samad et al., 2017). In short, a number of reasons that influence student's problems in completing TOEFL test especially in answering reading section are lack of basic skill, lack of vocabulary, lack of practice, less motivation, individual differences, and reading strategies.

\section{Method}

This research was quantitative research with descriptive design. It was designed to find out the information about the problems found in the field and try to analyze and describe it deeply. In this case, this study investigated and analyzed the students' difficulties in completing TOEFL ITP in reading sections as well as its reasons.

In university of Fort De Kock, there were 36 students of physiotherapy department. Using total sampling technique, all of these students were chosen as the samples. Two instruments used to collect the date, namely TOEFL test and questionnaire. For the first instrument, the data were collected through TOEFL PBT designed by ETS (English Testing Services) which can be downloaded in www.ets.org/toefl. This test was chosen since it is a reliable and credible source to measure the students' ability in English like the real ITP test. It consisted of three sections, namely the listening comprehension, the structure and written expressions, and the reading comprehension. All questions in each section were in the form of multiple choices. For the reading section, there were 50 questions that had to be answered within 55 minutes. It had five passages that covered seven types of questions: reference, inference, main idea, negative, factual, vocabulary, and scanning (Rogers, 2011). This test provided the answer for the problems encountered by the students in completing section three of TOEFL test.

The second instrument was questionnaire. The questionnaire was designed by adopting and adapting it from Ananda (2016) with some modifications to suit the objectives of this study. This questionnaire was given to the students after they had finished doing the TOEFL test. It was used to find out the causes of difficulties encountered by the students in completing reading comprehension section of ITP TOEFL.S

After getting the data, they were analyzed through a number of steps. For the first instrument, the TOEFL test, the answers given by the students were checked by calculating their reading score in each item. Then, the answers were classified into the correct answers and incorrect ones. After that, the percentages of the correct answers of each question were counted by using a formula proposed by Sudijono (2006):

$$
P=\frac{f}{N} \times 100
$$

In which:

$\mathrm{P}=$ percentages of correct answer in each indicator

$\mathrm{f}=$ the number of the correct answers in each indicator

$\mathrm{N}=$ total number of all of the correct answer

The indicators with the lowest percentages become the most serious problems faced by students. Then, the result of the percentages will be converted into classification from Arikunto (2006), p. 246) which is based on the questions indicator classification shown in Table $\mathbf{1}$. 
Table 1. Difficulty Classification

\begin{tabular}{cc}
\hline Difficulty Level (\%) & Classification \\
\hline $80 \leq P<100$ & Most Easy \\
$60 \leq P<80$ & Easy \\
$40 \leq P<60$ & Medium \\
$20 \leq P<40$ & Difficult \\
$0 \leq P<20$ & Most Difficult \\
\hline
\end{tabular}

For the second instrument, the questionnaire was conducted by classifying the answers "yes" and "no" for each item chosen by the participants. Then, the answers given were calculated and converted into percentages to ease the data analysis and data interpretation.

\section{Results}

\subsection{Test Results}

Having analyzed the data, it was found that all of the students had problems with scanning, reference question, main idea, factual question, inference question, vocabularies in-context, and negative question. Its analysis result can be seen in the following table:

Table 2. Reading Section of TOEFL Test Results

\begin{tabular}{clcccc}
\hline No & Types of Questions & Total of Item & $\begin{array}{c}\text { Total Correct } \\
\text { Answers }\end{array}$ & Percentage & Classification \\
\hline 1 & Vocabularies in-context & 13 & 138 & $29.4 \%$ & Difficult \\
2 & Factual question & 17 & 160 & $26.1 \%$ & Difficult \\
3 & Negative question & 5 & 62 & $34.4 \%$ & Difficult \\
4 & Inference question & 6 & 57 & $26.3 \%$ & Difficult \\
5 & Main Idea & 3 & 26 & $24.0 \%$ & Difficult \\
6 & Reference question & 4 & 26 & $18.0 \%$ & Most Difficult \\
7 & Scanning & 2 & 10 & $13.8 \%$ & Most Difficult \\
\hline
\end{tabular}

Table 2 displays the problems faced by the students in completing reading comprehension section of ITP TOEFL. From this table, it is seen that from seven types of reading comprehension questions tested, two types of questions; scanning $(13.8 \%)$ and reference question $(18.0 \%)$ are in the range of $0 \leq P<20$ and classified into the most the difficult questions, meanwhile the other five types of questions; main idea $(24.0 \%)$, factual question $(26.1 \%)$, inference question $(26.3 \%)$, vocabularies in-context $(29.4 \%)$, and negative question $(34.4 \%)$, are the range of $20 \leq P<40$ and categorized into difficult questions.

The first problem faced by the students was scanning. This type of question was classified into the most the difficult question. From 2 items of scanning question tested, there were only 10 correct answers $(13.8 \%)$ recorded. It occurred since the students faced difficulty at finding the correct information mentioned in the passage. In other words, such question was very difficult for the students.

The second problem encountered by the students was reference question. Such question was categorized into the most difficult question. From 4 items of reference question asked, there were only $18 \%$ correct answers. It occurred because the students had problems to find the reference of pronouns and other expressions in the passage.
The third problem faced by the students was the question related to main idea. This type of question was grouped into difficult question. From 3 items of main idea questions tested, there were only $24.0 \%$ of the students could answer them well. The students faced difficulty at determining the main idea of a paragraph or passage.

The fourth problem encountered by the students in reading comprehension section was factual question. This question type was classified into difficult question. From 17 items of factual questions asked, there were only $26.1 \%$ of the students could answer them correctly. That means the students had problems to find the correct answer for detail/specific information.

The fifth problem faced by the students was inference question. Such question was categorized into difficult question. From 6 items of inference questions tested, only $23.6 \%$ of the students could answer them well. It means the students had difficulty at making a conclusion based the information provided in the passage.

Another problem encountered by students was vocabularies in-context. This type of question was classified into difficult question. From 13 items of vocabularies incontext questions tested, there were only $29.4 \%$ of the students could answer them well. This means the students 
had problems with identifying the meaning of a word or phrase in the passage based on its context.

Finally, negative question was the next problem faced by the students. Negative question had the highest percentage of all items tested. However, it was still categorized into difficult type of question. From 5 items of negative questions asked, there were only $34.4 \%$ of the students could answer them correctly. It means the students still had problem to find clearly unstated information in the passage.

To sum up, in this research, all of the students had problems with the seven types of questions tested in reading comprehension section of ITP TOEFL. Generally, all types of questions in reading comprehension of ITP TOEFL were difficult for the students.

\subsection{Questionnaire Results}

After analyzing the data from the questionnaire, it was found that a number of causes of problems faced by the students in completing reading comprehension section of ITP TOEFL are feeling panic to face long passages, limitation of vocabularies, lack of practice, and less motivation. The result of the questionnaire analysis can be seen in Table 3.

Table 3. The Students' Reasons for the Reading Difficulties

\begin{tabular}{|c|c|c|c|}
\hline No & Statements & Yes & No \\
\hline 1. & $\begin{array}{l}\text { Section three (reading } \\
\text { comprehension is the most } \\
\text { difficult section for me }\end{array}$ & $57,9 \%$ & $42,1 \%$ \\
\hline 2. & $\begin{array}{l}\text { Section three (reading section) } \\
\text { is easier for me than section two } \\
\text { and one. }\end{array}$ & $31,6 \%$ & $68,4 \%$ \\
\hline 3. & $\begin{array}{l}\text { Section three (reading } \\
\text { comprehension is the most } \\
\text { difficult section for me because } \\
\text { I have to read long passages. }\end{array}$ & $73,7 \%$ & $26,3 \%$ \\
\hline 4. & $\begin{array}{l}\text { I feel bored and lazy to read } \\
\text { long passages. }\end{array}$ & $42,1 \%$ & $57,9 \%$ \\
\hline 5. & $\begin{array}{l}\text { I feel unfamiliar with most of } \\
\text { the words in section three. }\end{array}$ & $68,4 \%$ & $31,6 \%$ \\
\hline 6. & $\begin{array}{l}\text { I feel panic when facing long } \\
\text { English passages. }\end{array}$ & $57,9 \%$ & $42,1 \%$ \\
\hline 7. & $\begin{array}{l}\text { I feel familiar with English } \\
\text { because I usually use it in my } \\
\text { daily life. }\end{array}$ & $26,3 \%$ & $73,7 \%$ \\
\hline 8. & $\begin{array}{l}\text { I don't know the function of the } \\
\text { TOEFL score. }\end{array}$ & $31.6 \%$ & $68,4 \%$ \\
\hline 9. & $\begin{array}{l}\text { I think that TOEFL score is not } \\
\text { useful for my field of study }\end{array}$ & $15,8 \%$ & $84,2 \%$ \\
\hline 10. & $\begin{array}{l}\text { I never apply my English in my } \\
\text { daily life. }\end{array}$ & $63,2 \%$ & $36,8 \%$ \\
\hline
\end{tabular}

Table 3 shows the students' perception toward reading comprehension section of ITP TOEFL as well as the causes of the problems encountered by them. From this table, it is seen that $57.9 \%$ of the students regarded reading comprehension section as the most difficult section in ITP TOEFL. They $(68,4 \%)$ stated that reading comprehension was not an easy part for them.

Furthermore, this questionnaire revealed that there were a number of factors that influenced students' problems in completing reading section in ITP TOEFL. The first factor is long English passages. Most of the students (73.7\%) said that they had difficulty to read the long passages provided in the test. The second factor is limitation of the vocabulary. Most of the students $(68.4 \%)$ stated that they were not familiar with most of the words found in the passages. This condition made the students faced difficulty to understand the passage and answer the questions correctly. It indicates that the students had limited vocabulary. In other words, they had low vocabulary mastery. The third factor is lack of practice. From Table 3, it is seen that $73,7 \%$ of the students were unfamiliar with English and did not use English in their daily life. It indicates that the students seldom practiced their English. In other words, they had lack of practice. The last factor is less motivation. It is seen that only $31.6 \%$ students did not know the function of TOEFL score. It means that more than half of the students $(68,4 \%)$ knew the function of TOEFL score. In addition, most of the students $(84,2 \%)$ knew the use of TOEFL score for their field of study. In short, there were a number of factors that made the students face difficulty to answer the TOEFL test especially in reading comprehension section. They were feeling panic to face long passages, limitation of vocabularies, lack of practice, and less motivation.

\section{Discussion}

As the test results suggest all of the physiotherapy students of Fort De Kock University had problems with main idea, factual question, inference question, vocabularies incontext, negative question and serious problems with scanning and reference question. Scanning (13.8\%) and reference question $(18.0 \%)$ came as the questions types with the lowest percentages of errors, the lowest percentages become the most serious problems, faced by the students which were categorized into the most difficult questions, followed by main idea $(24.0 \%)$, factual question $(26.1 \%)$, inference question (26.3\%), vocabularies in-context (29.4\%), and negative question (34.4\%), respectively, as the types of questions with the lower percentages of errors encountered by them and classified into difficult questions.

Firstly, the most difficult question faced by the students was scanning (13.8) \%. This finding was in line with one of the findings of the study conducted by Maizarah (2019) who found that most of the students had problems in identifying stated detail questions and scanning questions. In addition, these two types of questions were also classified into the most difficult questions in her research. From the result of these two researches, it can be seen that most of the students had a problem in identifying the correct information in the text. 
Secondly, reference question was the next the most difficult question encountered by the students $(18 \%)$. This finding was in line with the finding of a research done by Nurhayati (2016) who found that reference question was a very difficult question for students. In her research, she found that there were only two students $(8 \%)$ could answer reference question correctly.

However, this finding contradicted with the finding of the study conducted by Perez-Amurao (2011) who found that reference questions were categorized into easy items since the students could answer them well. This difference happened due to a number of reasons. First, the type of this question was commonly found in their reading task so that the students were familiar with it. Then, it required the lowthinking skills because they only made a simple matching of the term in question and its referent in the passage. Referring to this last reason, it seems that reference question can be categorized into easy question since it does not need high thinking-skills so that the students do not need to think deeply. It seems that physiotherapy students in Fort De Kock University and the students in Nurhayati's research (2016) did not have adequate English knowledge and skill particularly related to reference so that such question became one of the serious problems faced by them.

Thirdly, the difficult question faced by the students was main idea (24.0\%).. This research result was contradictory to a research finding conducted by Fajri (2019). In his research, he found that $85 \%$ of the students could answer the questions about main idea correctly. The difference between these two results of the study may occur due to the different English mastery particularly related to main idea. It seems that the students in Fajri's study (2019) had better English skills particularly related to determining main idea.

Fourthly, the next difficult question encountered by the students was factual question $(26.1 \%)$. Such finding was along with the researches undertaken by Maizarah (2019) and Asrida (2019). In Maizarah's study (2019), the problem faced by the students in identifying stated detail (factual question) was categorized into the most difficult question since most of the students had problem with this type of question while in Asrida's study (2019), factual question was grouped into medium questions since not all of the students had difficulty to find the correct answer related to this question. From these three studies, it can be concluded that the students had problems with factual question with the most difficult, difficult, and medium difficulty classification.

Fifthly, the students had difficulty in answering the question about inference question (23.6\%). This research result was in line with the research results conducted by Perez-Amurao (2011) and Warnidah (2016). In PerezAmurao's research (2011), the problem faced by the students in inference question included extremely difficult question and was ranked as the second most difficult question as most of the students faced difficulty at integrating the information beyond the text provided as well as interpreting the text well. Similarly, in Warnidah's research (2016), inference question was classified into moderate (medium) since not all of the students had problems with this type of question. From these three researches, it can be summarized that the students had problems with inference question with the most difficult, difficult and moderate (medium) difficulty categorization

Sixthly, vocabularies in-context was the next problem faced by the students $(29.4 \%)$ This finding was in line with one of the findings of Halim \& Ardiningtyas (2018).In their research, they found that most of the students had problem with this type of question due to low mastery of English vocabularies the students had; consequently, they had problems to know the synonym of the words or phrases in the passage. In addition, they did not understand what the passage discussed due to the lack of vocabulary they had so that they faced more trouble when interpreting the meaning a word based on its context without knowing the meaning of the passage. In short, most of the students had problem with vocabularies in-context question due to limitation of vocabularies they had.

Lastly, the problem faced by the students in reading comprehension of ITP TOEFL was negative question $(34,4 \%)$. This finding contradicted with the finding of the study conducted by Maizarah (2019) who found that $77 \%$ of the students in her research were able to answer the negative questions correctly. Although not all of the students in her research could answer this type of question well but most of them $(77 \%)$ indicated that the students in her research had better English mastery especially regarding to finding unstated detail information in the passage.

Furthermore, regarding to the causes of the problems, , the questioner revealed a number of reasons why reading section of ITP TOEFL was difficult for the students. First, they were feeling panic to read the long passage (73\%) Since there were five long passages available in ITP TOEFL test consisting of 50 questions related to those passages, the students faced difficulty to read and understand them all with limited time. In this case, they did not feel lazy or bored to read but they (57.9\%) felt panic to face those long passages. This finding was in line with the studies conducted by Girsang et al. (2019) and Jayanti (2016). In their research, Girsang et al. (2019) found that the students felt bored to see the long text in front of them and it was hard for them to find the meaning of the text due to several reasons. Similarly, Jayanti (2016) in her research revealed that long sentences in the passages made the students confused and difficult to create meaning that is easy for them to understand. From these three researches, it can be concluded that long passage was one of the causes of the problems encountered by students in completing reading comprehension section of ITP TOEFL.

The second cause of the problems is the limitation of vocabularies $(68.4 \%)$. This finding was in line with the finding of Jayanti (2016) and Masfufah (2018). In Jayanti's study, she found that lack of lexical knowledge is one of the problems faced by the students in reading comprehension tests. She also added that some students tried to look up the 
dictionary when they found a new word so that they got trouble to understand the whole passages without checking the dictionary. Likewise, in her study, Masfufah (2018) revealed that most of the students did not know the meaning of the vocabularies found in the questions of TOEFL. These two findings as well as this current finding assert that limitation of vocabularies is another factor contributed to the difficulty in completing ITP TOEFL particularly on reading comprehension section.

The third factor that caused the students' difficulty is lack of practice. Most of the students (73.7\%) admitted that they had lack of practice. In fact, in learning a language, practice is a must since lack of practice contributed to reading difficulties encountered by the students. Moreover, the more someone practices a language, the more she/he masters the language. Related to ITP TOEFL test, the students had never practiced doing such kind of test. In fact, they had never done the test before so that their score of TOEFL test particularly on reading section became low.

The last cause of the difficulty is less motivation. Most of the students $(68,4 \%)$ knew the function of TOEFL score and $84,2 \%$ of them knew the use of TOEFL score for their field of study. It indicates that they realized the use and the importance of TOEFL score that can be used for certain purposes, for example, to complete their study, to continue their study, and to get a job. Although they knew the importance of TOEFL score, their TOEFL score particularly on reading section was still low. It seems that it was due to less motivation they had. They did not have strong motivation since most of their reason taking TOEFL test was only a requirement from their university so that they did not make extra efforts for that. The result of this research was similar with the finding of the study undertaken by Dewi et al. (2015). In their study, they found that even though the students knew the importance of English and had motivation in English; In fact, their TOEFL score was still low. Ideally, when the students knew the importance of English and had motivation in English, they should have good English skills and high TOEFL score. In fact, it did not happen. It indicates that knowing the importance of English and having good motivation in English does not always correlate with high TOEFL score obtained.

Based on the explanation above, it is seen that the findings of the current research have both similarities and differences with the previous researches. The similarity is that this study is along with the finding of several previous studies (Maizarah, 2019; Halim \& Ardiningtyas, 2018; Asrida, 2019; Nurhayati, 2016; Warnidah, 2016; PerezAmurao 2011) that students had problems with scanning, vocabularies in-context, factual question, reference question, inference question of reading comprehension section of TOEFL. In contrast, the finding of this current study is contradictory with the findings of other previous studies (Fajri, 2019; Maizarah, 2019; Perez-Amurao 2011) that students did not have serious problems on main idea, negative question, and reference question. In this study, they had serious problems on those types of questions.

Another difference is that all of the physiotherapy students in this study had serious problems with all types of questions tested in reading comprehension section of ITP TOEFL. From seven types of questions tested, five types of questions were categorized into difficult questions and the other two types of questions were classified into the most difficult questions. It means the test of reading comprehension section was difficult and very difficult for them. When all types of questions tested were grouped into difficult and very difficult questions indicated that all of the students did not have good English proficiency. In other words, they had low basic English mastery. Hence, these problems need to be concerned.

Concerning with the problems encountered, it is important for the students to improve their English knowledge and skills on reading comprehension section of ITP TOEFL by doing a number of efforts. First, the students can do exercises and practice doing reading comprehension questions models from the TOEFL books or other reliable material sources before taking the test so that they know the types of questions of reading comprehension tested and are accustomed to having them. Then, it is better for students to always improve their vocabulary mastery especially related to reading comprehension section. Although the types of reading usually change from one test to another, nevertheless there are a number of common vocabularies used either on the questions or the reading itself. It can be done through regularly practicing doing the questions of reading comprehension models, taking notes essential words, finding their meaning, and memorizing them for a couple of weeks before the test held.

Next, the students need to learn good strategies how to do reading comprehension test since it is one of factors that influences the TOEFL score obtained. Nazri \& Wijaya (2020) found that one of the factors that made most of the students had low score in TOEFL was that they did not know the good strategy in doing it. Most of them read whole of the text which spent their lot of time. In line with this idea, Zalha \& Alfiatunnur (2020) explained that having appropriate strategies is one way to solve the problems in every section in TOEFL test, include reading comprehension section. Besides, they need to change their paradigm and grow awareness that joining TOEFL test is not only to fulfill the requirement from their university but also to improve their English ability which provides useful prospect for their future. Having such kind of thinking in their mind makes them get motivated to prepare and provide more attention in learning ITP TOEFL particularly on reading comprehension section.

Furthermore, it is important for English instructors to provide more study exercises and practices on doing reading comprehension section for their students. Then, enrichment especially for the types of questions which are regarded the most difficult for the students should also be given. In 
addition, it is better for the English instructors to provide their students with various better strategies how to answer the questions of TOEFL test especially on reading comprehension section.

\section{Conclusion}

Based on the results of the test, questionnaire and discussion, it can be concluded that there were a number of problems faced by non-English students namely physiotherapy students in completing reading comprehension section of ITP TOEFL The problems were scanning, reference question, main idea, factual question, inference question, vocabularies in-context, and negative question. From these problems, scanning and reference question were classified into the most difficult questions faced by the students. Meanwhile, the rests, main idea, factual question, inference question, vocabularies in-context, and negative question were categorized into difficult questions. Furthermore, there were a number of factors that caused the students had problems in completing reading comprehension section of ITP TOEFL First, the reading comprehension section had long passages. Then, the studsents had limitation of vocabularies. Next, the students had lack of practice. Finally, they had less motivation.

At last, it is realized that this research still has a number of limitations. First, there was a limitation of population. Therefore, the result of this research cannot be generalized to the wider population. Second, the questionnaire consisted of small indicators so that it cannot explore the students' reasons more deeply. Due to those limitations, it is suggested to the next researchers to conduct further studies on other students out of English department in completing ITP TOEFL test by involving larger subject. Then, for educators, it is suggested to motivate their students to improve their ability in English especially related to ITP TOEFL. It can be done by practicing English every day on their daily life, improving their basic skills, and searching for information about the importance of the TOEFL score for their future.

\section{Acknowledgement}

The authors give thanks to the physiotherapy students at Fort De Kock University who had participated this research. Then, to Fort De Kock University that has given a chance to conduct the research and all of the parties who have provided facilities and assistance for the accomplishment of this article. Hopefully, this article is beneficial and can be used as an input for teachers and trainers who teach English as a foreign language. Constructive criticism and suggestions will be accepted to improve this for future research.

\section{References}

Ananda, R. (2016). Problems With Section Two ITP TOEFL Test. Studies in English Language and Education, 3(1), 37. https://doi.org/10.24815/siele.v3i1.3387

Antoni, Ri. (2014). An Analysis on 6th Semester Students' TOEFL Experience at English Department of Teachers
Training and Education of Pasir Pangairan University. Jurnal Ilmiah Edu Research, 3(1), 9-16.

Arikunto, S. (2006). Metode Penelitian Kualitatif. Bumi Aksara.

Asrida, R. (2019). The Difficulties of English Department Students at Universitas Negeri Padang in Answering Reading Section of TOEFL. Jurnal of English Language Teaching, 8(4), 2-9.

Dewi, I. I., Darna, D., \& Suprato, D. (2015). The Changes of Students' Toefl Score After One Year Learning. Humaniora, 6(4), 507. https://doi.org/10.21512/humaniora.v6i4.3379

Fajri, D. R. (2019). an Analysis of Student Strategy in Completing Toefl Reading Comprehension Test. Journal of English Language Teaching and Literature (JELTL), 2(2), 84-91. https://doi.org/10.47080/jeltl.v2i2.598

Febriani, D., Elfrida, E., \& Jayanti, F. G. (2019). Reading Comprehension Problems in Reading Section of Toefl Test. JALL (Journal of Applied Linguistics and Literacy), 3(2), https://doi.org/10.25157/jall.v3i2.2537

Girsang, A. L., Marbun, F. V. G., Turnip, Y. A. M., \& Saragih, E. (2019). An Analysis of Reading Comprehension Difficulties in TOEFL Test By High School Students. Linguistic, English Education and Art (LEEA) Journal, 3(1), 132-137. https://doi.org/10.31539/leea.v3i1.1002

Halim, N., \& Ardiningtyas, S. Y. (2018). Difficulties faced by the students in answering toefl test questions. English, Teaching, Learning, and Research Journal, 4(2013), 219-231.

Jayanti, F. G. (2016). Reading Difficulties: Comparison on Students and Teachers Perception. Fourth International Seminar OnEnglish Language and Teaching, 296-301. ejournal.unp.ac.id/index.php/selt/article/view/6939

Lestari, S. \& S. (2017). A Narrative Research: A Student's Strategies in Reading Comprehension on TOEFL at the Eight Semester of English Education Departement of Lancang Kuning University. ELT-Lectura: Jurnal Pendidikan, 4(2), 785. https://doi.org/10.6009/jjrt.KJ00003534360

Maizarah. (2019). Analysis of Common Difficulties in TOEFL Reading Comprehension (A Case Study on the Second Semester Students of English Study Program Islamic University of Indragiri. English Journal of Indragiri (EJI), 3(3), 55.

Masfufah, S. (2018). Indonesian Collage Students' Perception of TOEFL Preparation Class. Journal of English Education, Literature, and Culture (EDULITE), 3(1), 66-78.

Meladina, Z. A. (2013). The Integaration of Character 
Education into Teaching Reading Hortatory Test. Journal of English Language Teaching, 2(September), 186-194.

Nazri, M. A., \& Wijaya, H. (2020). EFL Students ' Ability in Answering TOEFL Reading Comprehension Section EFL Students' Ability in Answering TOEFL Reading Comprehension Section. Journal of Physics: Conference Series, 1539(2020). https://doi.org/10.1088/1742-6596/1539/1/012044

Noviyenty, L. (2018). An Evaluation of TOEFL Matriculation Program For STAIN Students. English and Literature Journal (ELITE), 05(01), 55-68.

Nurhayati, N. (2016). An Analysis of Students' Strategies in Answering TOEFL. The Journal of English Language Studies, 01(01), 10-18.

Perez-Amurao, A. (2011). The Types and Nature of Questions vis-à-vis Students' Test-Taking Skills as Significant Indicators of Second Language Examinees? Performance on the TOEFL-ITP Reading Comprehension Sub-Test. The International Journal of Research and Review, 6(2), 39-56.

Rogers, B. (2011). The Complete Guide to the TOEFL Test (T. Jefferies (ed.); PBT Editio). Sherrise Roehr.

Samad, I. A., Jannah, M., \& Fitriani, S. S. (2017). Efl students' strategies dealing with common difficulties in toefl reading comprehension section. International Journal of Language Education, 1(1), 29-36. https://doi.org/10.26858/ijole.v1i1.2869

Sari, D. F. (2019). The Strategy of Two Stay Two Stray to Improve EFL Students, Reading Skill. Studies in English Language and Education, 6(1), 171-184.

Services, E. T. (n.d.). TOEFL. Retrieved September 20, 2020, from https://www.ets.org/TOEFL/

Sudijono, A. (2006). Pengantar Statistik Pendidikan. PT Raja Grafindo.

Sungatullina, D. D., Zalyaeva, E. O., \& Gorelova, Y. N. (2016). Metacognitive awareness of TOEFL reading comprehension strategies. SHS Web of Conferences, 26 , 01046. https://doi.org/10.1051/shsconf/20162601046

Warnidah, N. (2016). Students 'Difficulties in Making Inference in Reading Narrative Passages at the Social Elevent Grade of SMAN 1 Curup. Journal of Applied Linguistics and Literature, 2(2), 78-94.

Zalha F.B., Alfiatunnur., K. C. A. (2020). Strategies in Dealing with the Reading Section of 'TOEFL Prediction': A Case of Aceh EFL Learners. IJEE (Indonesian Journal of English Education, 7, 159171. https://doi.org/10.17622/ijee.v7i2.17622 